\title{
Long-term prognosis of breast cancer detected by mammography screening or other methods
}

Tiina Lehtimäki ${ }^{*}$, Mikael Lundin ${ }^{1}$, Nina Linder ${ }^{1}$, Harri Sihto ${ }^{2}$, Kaija Holli ${ }^{3}$, Taina Turpeenniemi-Hujanen ${ }^{4}$, Vesa Kataja ${ }^{5}$ , Jorma Isola ${ }^{6}$, Heikki Joensuu ${ }^{1,7}$ and Johan Lundin ${ }^{1,8}$

\begin{abstract}
Introduction: Previous studies of breast cancer have shown that patients whose tumors are detected by mammography screening have a more favorable survival. Little is known, however, about the long-term prognostic impact of screen detection. The purpose of the current study was to compare breast cancer-specific long-term survival of patients whose tumors were detected in mammography screening compared with those whose tumors were detected by other methods.

Methods: Breast cancer patients diagnosed within five specified geographical areas in Finland in 1991 and 1992 were identified ( $N=2,936)$. Detailed clinical, treatment and outcome data, as well as tissue samples, were collected. Women with in situ carcinoma, distant metastases at the time of primary diagnosis and women who were not treated surgically were excluded. The main analyses were performed after excluding patients with other malignancy or contralateral breast cancer, followed by sensitivity analyses with different exclusion criteria. Median follow-up time was 15.4 years. Univariate and multivariate analyses of breast cancer-specific survival were performed.
\end{abstract}

Results: Of patients included in the main analyses $(n=1,884), 22 \%(n=408)$ of cancers were screen-detected and $78 \%(n=1,476)$ were detected by other methods. Breast cancer-specific 15-year survival was $86 \%$ for patients with screen-detected cancer and 66\% for patients diagnosed using other methods $(P<0.0001, H R=2.91)$. Similar differences in survival were observed in women at screening age (50 to 69 years), as well as in clinically important subgroups, such as patients with small tumors ( $\leq 1 \mathrm{~cm}$ in diameter) and without nodal involvement (N0). Women with breast cancer diagnosed on the basis of screening mammography had a more favorable prognosis than those diagnosed outside screening programs, following adjustments according to patient age, tumor size, axillary lymph node status, histological grade and hormone receptor status. Significant differences in the risk of having future contralateral breast cancer according to method of detection were not observed.

Conclusions: Breast cancer detected by mammography screening is an independent prognostic factor in breast cancer and is associated with a more favorable survival rate as well as in long-term follow-up.

Keywords: screening, mammography, prognosis, survival analysis

\section{Introduction}

Breast cancers detected by screening mammography have more favorable prognostic characteristics than cancers detected by other methods [1-9]. The tumors are smaller, are more often well-differentiated, show less spread to regional lymph nodes and have a lower

\footnotetext{
* Correspondence: tiina.lehtimaki@helsinki.fi

${ }^{1}$ Institute for Molecular Medicine Finland (FIMM), University of Helsinki, Biomedicum Helsinki 2U, Tukholmankatu 8, PO Box 20, Fl-00014 Helsinki, Finland

Full list of author information is available at the end of the article
}

proliferation index [1,2,10-16]. In addition, a large proportion of screen-detected tumors are of luminal type $\mathrm{A}$, and relatively few are of the human epidermal growth factor receptor 2-positive/estrogen receptor-negative (HER2+/ER-) molecular subtype [9]. Studies have shown the method of detection to be an independent prognostic factor, even after adjustment for a series of established prognostic variables $[9,17,18]$.

In a recently published study of 2,592 Dutch breast cancer patients, screen detection was reported to be independently associated with better breast cancer-

\section{Biomed Central}


specific and overall survival after a median follow-up of 11 years [18]. We observed similar results in our previous study [17] in which patients with screen-detected breast cancer had significantly better distant disease-free survival than patients whose tumors were detected by other methods. Adjustments for several known prognostic factors were made in both studies, which reduced the effect of lead time and length biases. Screening as a method of detection has been considered an independent prognostic factor in several other studies [3,12,19-21].

Most breast cancer recurrences occur 2 to 3 years after diagnosis [22], but the disease recurs even 15 to 25 years after diagnosis in some patients [23-25]. A timedependency has been reported for prognostic factors such as ER status, tumor size, lymph node status and tumor grade, whereby the prognostic value may decrease with time [22,26,27]. Researchers in only a few studies over longer follow-up periods have analyzed the prognostic value of the method of tumor detection.

Most of the data derived from previous studies in which long-term outcomes of breast cancer detected within screening programs were analyzed are from clinical trials that reported mortality [28]. Only very few of the previous studies on screen detection and breast cancer prognosis focused on long-term survival of the patients (beyond 15 years from diagnosis) [3,29]. In these studies, the favorable survival of screen-detected cancers persisted over time. The data were adjusted for extent of disease, but not for a more detailed clinical, pathological or molecular profile.

There has been disagreement on the observed mortality and survival differences between patients whose breast cancer was detected by mammography and those whose breast cancer was detected outside screening, owing to biases in the statistical analysis [30-33]. In the context of patient survival, cancers found by screening mammography are detected earlier during their natural history and are therefore susceptible to lead time bias. In breast cancer, the lead time is estimated to be approximately 3 to 4 years [34]. The other main bias, duration bias, implies that slowly growing tumors are more likely to be detected by screening because they remain asymptomatic but detectable by mammography for a longer time [32,35].

Screen-detected cancers may be subject to selection bias in that true attendees may represent not the entire population, but rather a generally more health-conscious population. In addition, screening may lead to detection of indolent cancers that would never have caused symptomatic disease and therefore they are overdiagnosed.

In the present study, our aim was to evaluate whether the survival advantage of patients with screen-detected cancers persists after long-term follow-up. For this purpose, we analyzed an unselected nationwide series of breast cancer patients, which was recently updated to include long-term follow-up data. In previous studies of screen detection and survival, various definitions of screen-detected breast cancer have been used. In some studies, for example, outcomes of invited women and noninvited women have been compared [36], or interval cancers have been included in the screen-detected group [20,37], instead of the outcomes of true screening attendees with the outcomes of patients with cancer detected by other methods [36]. In the current study, we used hospital records to retrieve information about the method of detection and compared the survival of true attendees with the survival of patients with cancers detected outside screening. Survival estimates were adjusted according to an extensive series of factors known to reflect the extent of disease to reduce the effect of both lead time and length time biases. In addition, we analyzed the occurrence of contralateral breast cancer according to the method of tumor detection.

\section{Material and methods \\ Patients}

Five well-defined geographical areas comprising approximately $50 \%$ of the Finnish population were selected for the study. We identified 2,936 patients diagnosed with breast cancer in 1991 and 1992 from the files of the Finnish Cancer Registry, which constitutes 53\% of all women diagnosed with breast cancer in Finland during that time period $(N=5,551)$. Permission to use clinical data and formalin-fixed, paraffin-embedded tissues for research purposes was provided by the Ministry of Social Affairs and Health, Finland (permission 123/08/ 97). With reference to the large number of studied cases, the authorities granted permission to use tissue samples without individual patient consent.

Clinicopathological data were extracted from the hospital records by using data collection forms, and tumor tissue samples from each patient's cancerous tissue were collected for tumor microarrays [38] as previously described in detail $[9,17]$. Outcome and cause of death data were compiled from the files of the Finnish Cancer Registry and Statistics Finland.

Of the 2,936 patients, 14 were excluded because of zero follow-up time due to perioperative mortality or diagnosis at autopsy. In 46 patients (2\%), incorrect diagnoses were recorded during data extraction and thus were also excluded. The remaining 2,883 patients formed the FinProg database, which has previously been published and made available as an online case-match prognostic tool http://www.finprog.org/. Of the 2,883 patients, $131(5 \%)$ had distant metastases at the time of diagnosis and were excluded. Patients who were not treated surgically $(n=101,4 \%)$ and patients with lobular 
or ductal carcinoma in situ $(n=209,7 \%)$ were excluded. Those with missing data on exclusion variables were excluded, except for missing metastasis status. All of the exclusion criteria mentioned above were used in subsequent analyses.

In patients with contralateral breast cancer or other cancer, the true origin of potential distant metastases may be difficult to determine. For the main analyses, patients with previous, synchronous or later contralateral invasive breast carcinoma were excluded $(n=349$, $12 \%)$. Furthermore, we excluded patients with recent, synchronous or later other cancers $(n=301,10 \%)$, except for cervical carcinoma in situ and basal cell carcinoma. We defined other cancer as recent if it had been diagnosed within 5 years before the index breast cancer. Thus all patients with other carcinoma diagnosed after 1 January 1985 were excluded. The total number of patients included in the main analyses was 1,934.

For the first sensitivity analyses, we excluded patients with contralateral breast cancer only if it had been diagnosed before or at the same time as the index breast cancer $(n=168,6 \%)$. We also excluded patients with other carcinoma only if it was recent (1985 and later) or synchronous $(n=44,2 \%)$. For the second sensitivity analyses, we included all patients with contralateral breast cancer or other cancer or both and used only the primary exclusion criteria mentioned above $\left(\mathrm{M}_{+}\right.$, no surgery, ductal carcinoma in situ and lobular carcinoma in situ). In all analyses, one patient could have been excluded for several reasons. The consort diagrams of the study are given in Additional file 1. We used breast cancer-specific survival (BCSS) as an outcome measurement. The median follow-up time of surviving patients was 15.4 years.

\section{Method of detection}

A screening mammography program was launched in Finland in 1987. During 1991 and 1992, Finnish municipalities were obligated by legislation to organize mammography screening programs for women 50 to 59 years of age. A few of the municipalities, however, screened other age cohorts as well (women 40 to 49 years and/or older than 60). The information regarding the method of detection in the FinProg series was collected from hospital records and from the Mass Screening Registry, which is a department of the Finnish Cancer Registry. Consequently, in the FinProg database, patients diagnosed within the mammography screening program are patients who have been invited to have and also truly attended screening mammography.

For cancers diagnosed on the basis of symptoms, as interval cancers between screening rounds or for any other reason outside the mammography screening program, we use the term "detected outside screening" or "non-screen-detected breast cancer." Screening round was not considered in this study.

\section{Histopathological characteristics}

Postsurgical tumor size was recorded according to information extracted from hospital records. Tumor measurements were done in the following order of priority: on tumor slides by a pathologist, at the time of surgery by a surgeon, on the basis of $\mathrm{x}$-ray mammography by a radiologist or by clinical palpation. The largest tumor diameter was recorded as its postsurgical size. In the main analyses, there were $1,262(65 \%)$ breast cancers whose tumor measurements were done by the pathologist on the basis of tumor slides. Similar distributions of methods of measurement were seen in both screen-detected and non-screendetected breast cancers, where 267 (65\%) and 974 (66\%) tumor measurements, respectively, were done by a pathologist and $86(21 \%)$ and 301 (20\%), respectively, were done by a surgeon. More tumors were screen-detected when measured by a radiologist $(n=32,8 \%)$ than when diagnosed by other methods $(n=68,5 \%)$. Palpation as a method of measurement was used in 5 patients (1\%) diagnosed by screening mammography compared to 51 patients (4\%) diagnosed on the basis of other methods (Additional file 2, Table S1). Histological typing and evaluation of the grade components (mitotic cell count, nuclear pleomorphism and tubule formation) were usually performed according to the World Health Organization classification [39], although the criteria used in tumor classification cannot be stated with certainty in retrospect. The tumors were classified into three histological types: ductal carcinoma (not otherwise specified, including apocrine, mixed mucinous and atypical medullary types), lobular carcinoma (infiltrating lobular carcinoma with variants) and the special histological types (tubular, medullary, cribriform, papillary and pure mucinous carcinomas).

\section{Laboratory methods}

Immunohistochemical (IHC) staining, evaluation of protein expression and in situ hybridization were performed as described in detail elsewhere $[9,17,40,41]$. According to recent recommendations by the American Society of Clinical Oncology, immunostaining of hormone receptors was considered positive when at least $1 \%$ of the cancer cells showed staining and negative when less than $1 \%$ of the cancer cells were stained [42]. For the other biomarkers, IHC expression was considered negative when less than $10 \%$ of tumor cell nuclei expressed protein, except for Ki-67 and p53, for which we used a cutoff of $20 \%$.

\section{Statistical analysis}

Frequency tables were analyzed using the $\chi^{2}$ test. Life tables were calculated according to the Kaplan-Meier 
method. BCSS was computed from the date of the diagnosis until death due to breast cancer. The logrank test was used to compare survival between subgroups. Multivariate survival analyses were performed using a Cox proportional hazards model by entering the following covariates: method of tumor detection (mammography screening $=0$, outside screening $=1$ ), grade (well-differentiated $=0$, moderately or poorly differentiated $=1$ ), $\mathrm{ER}$ and progesterone receptor $(\mathrm{PR})$ status (positive $=0$, negative $=1$ ), histological type (lobular or special $=0$, ductal $=1$ ), and age at detection grouped to account for the nonlinear risk associated with age. The tumor size in centimeters and the number of metastatic axillary lymph nodes were entered into the multivariate model as continuous variables. Multivariate analysis of the risk of later contralateral breast cancer was performed using logistic regression by entering the same covariates into the model as were entered into the Cox proportional hazards model. A $P$-value of 0.05 was adopted as the limit for inclusion of a covariate. All $P$-values are twosided. STATA version 10 statistical software (StataCorp, College Station, TX, USA) was used for the analyses.

\section{Results}

\section{Method of tumor detection and clinicopathological features}

In the main study series $(N=1,884), 408$ patients $(22 \%)$ had screen-detected breast cancer and 1,476 (78\%) had non-screen-detected breast cancer. Mammography screening is organized mainly for women 50 to 69 years of age. In the current series, 484 patients $(26 \%)$ were ages 50 to 59 years and $365(19 \%)$ were ages 60 to 69 years. Of these patients, 254 (52\%) and 93 (25\%) were patients with screen-detected cancer, respectively, and $230(48 \%)$ and 272 (75\%) had non-screen-detected cancer, respectively.

The median tumor size for the entire cohort was 20 $\mathrm{mm}$. The median tumor size was $13 \mathrm{~mm}$ among screendetected tumors, and it was $20 \mathrm{~mm}$ in non-screendetected tumors. Eighty-three percent of screen-detected tumors were $20 \mathrm{~mm}$ or less (T1), compared to only $53 \%$ of non-screen-detected tumors.

Nodal involvement was less frequent in patients with screen-detected breast cancer than in non-screendetected breast cancer $(21 \%$ vs $37 \% ; P<0.001)$, which was also true among women 50 to 69 years of age (20\% vs $35 \% ; P<0.001)$. Among the screen-detected cancers, $66 \%$ of tumors were $20 \mathrm{~mm}$ or less and had no nodal involvement (T1N0), and only $36 \%$ of non-screendetected cancers belonged to this category.

The majority of screen-detected tumors were ductal carcinomas (70\%). However, the proportion of ductal carcinomas was significantly higher $(75 \% ; P<0.04)$ in non-screen-detected cancers. The proportion of lobular carcinomas (16\%) was equal in both diagnostic groups. Screen-detected tumors were more often of a special histological type $(14 \%$ vs $9 \% ; P<0.04)$. Similar differences in histological profile were seen in the 50- to 69year-old age cohort (ductal: $70 \%$ vs $73 \%$; lobular: $16 \%$ vs $19 \%$; special type: $14 \%$ vs $8 \% ; P=0.02$ ).

Tumors detected by mammography screening were more often of a lower grade of differentiation. There were 129 grade 1 breast cancers $(32 \%)$ in the screendetected group and $241(16 \%)$ among tumors detected by other methods $(P<0.001)$. Correspondingly, screendetected cancers were less often grade 2 or 3 tumors ( $n$ $=202,49 \%)$ than were non-screen-detected cancers $(n=$ $841,57 \%)(P<0.001)$. However, this association weakened with increasing tumor size (Additional file 2, Table S2). In T1N0 tumors, 36\% of screen-detected tumors were well-differentiated, but only $22 \%$ in the non-screen-detected group were. In patients with larger tumors, such as T2 tumors (21 to $50 \mathrm{~mm}$ ), the proportion of G1 tumors was equal in both diagnostic groups (11\%) and the proportion of G2-3 tumors was $75 \%$ in screen-detected tumors compared to $64 \%$ in nonscreen-detected tumors $(P=0.77)$.

Screen detection was associated with hormone receptor status (ER and PR), although in analyses consisting of all age groups, the association was weak $(P=0.038$ and $P=0.094$, respectively). In women at screening age (50 to 69 years), there were only 9\% ER-tumors in screen-detected tumors compared to $19 \%$ in nonscreen-detected tumors $(P=0.002)$. Similar differences were seen according to PR status $(P<0.001)$.

No statistically significant association between screen detection and HER2 gene amplification or p53 expression was seen in any of the analyzed age groups. Somewhat fewer Ki-67-positive tumors were seen in screendetected breast cancers compared to those detected outside screening ( $18 \%$ vs $26 \%$ ), but the association was not statistically significant $(P=0.08)$.

Adjuvant systemic therapy was given less frequently to patients with screen-detected breast cancer than to women with non-screen-detected breast cancer $(22 \%$ vs $41 \% ; P<0.001)$. The use of adjuvant systemic therapy was not known in 5 patients $(1 \%)$ with screen-detected cancers and in 40 patients (3\%) with non-screendetected cancers.

In women 50 to 69 years of age, screen detection was statistically significantly associated with smaller primary tumor size, less frequent lymph node metastasis, special histological type, lower grade of differentiation and positive hormone receptor status (ER and PR) compared with non-screen-detected cancers. The distribution of clinicopathological features in women with breast cancer diagnosed by screening mammography and by other methods is shown in Table 1. 
Table 1 Descriptive statistics for main analyses $(N=1,884)$

\begin{tabular}{|c|c|c|c|c|c|c|}
\hline \multirow[b]{2}{*}{ Factor } & \multicolumn{3}{|c|}{ All age groups } & \multicolumn{3}{|c|}{ Ages 50 to 69 years } \\
\hline & $\begin{array}{l}\text { Screening, } n(\%)^{\mathrm{a}} \\
(n=408)\end{array}$ & $\begin{array}{l}\text { Outside screening, } n \text { (\%) } \\
(n=1,476)\end{array}$ & $P$ value & $\begin{array}{l}\text { Screening, } n(\%) \\
(n=347)\end{array}$ & $\begin{array}{l}\text { Outside screening, } n(\%) \\
\quad(n=502)\end{array}$ & $P$ value \\
\hline Primary tumor diameter $(\mathrm{mm})$ & & & $<0.001$ & & & $<0.001$ \\
\hline$\leq 10$ & $158(39)$ & 207 (14) & & $143(41)$ & $82(16)$ & \\
\hline 11 to 20 & $179(44)$ & $576(39)$ & & $147(42)$ & $204(41)$ & \\
\hline 21 to 50 & $55(13)$ & $581(39)$ & & $42(12)$ & $183(36)$ & \\
\hline$>50$ & $2(0)$ & $66(4)$ & & $1(0)$ & $21(4)$ & \\
\hline N.A. & $14(3)$ & $46(3)$ & & $14(4)$ & $12(2)$ & \\
\hline Nodal status & & & $<0.001$ & & & $<0.001$ \\
\hline Negative & $317(77)$ & $862(58)$ & & $273(79)$ & $321(64)$ & \\
\hline Positive & $85(21)$ & $552(37)$ & & $69(20)$ & $178(35)$ & \\
\hline N.A. & $6(1)$ & $62(4)$ & & $5(1)$ & $3(0)$ & \\
\hline Histological type & & & 0.04 & & & 0.02 \\
\hline Ductal & $287(70)$ & $1,104(75)$ & & $243(70)$ & $365(73)$ & \\
\hline Lobular & $65(16)$ & $232(16)$ & & $55(16)$ & $95(19)$ & \\
\hline Special type & $56(14)$ & $139(9)$ & & $49(14)$ & $41(8)$ & \\
\hline N.A. & 0 & $1(0)$ & & 0 & $1(0)$ & \\
\hline Histological grade & & & $<0.001$ & & & $<0.001$ \\
\hline 1 & $129(32)$ & $241(16)$ & & $111(32)$ & $85(17)$ & \\
\hline 2 & $147(36)$ & $515(35)$ & & $123(35)$ & $172(34)$ & \\
\hline 3 & $55(13)$ & $326(22)$ & & $43(12)$ & $115(23)$ & \\
\hline N.A. & $77(19)$ & $394(27)$ & & $70(20)$ & $130(26)$ & \\
\hline ER content & & & 0.038 & & & 0.002 \\
\hline Negative & $40(10)$ & $232(16)$ & & $31(9)$ & $94(19)$ & \\
\hline Positive & $204(50)$ & $802(54)$ & & $172(50)$ & $260(52)$ & \\
\hline N.A. & $164(40)$ & $442(30)$ & & $144(41)$ & $148(29)$ & \\
\hline PR content & & & 0.094 & & & $<0.001$ \\
\hline Negative & 79 (19) & $392(27)$ & & $64(18)$ & $171(34)$ & \\
\hline Positive & $161(39)$ & $620(42)$ & & $132(38)$ & $173(34)$ & \\
\hline N.A. & $168(41)$ & $464(31)$ & & $151(44)$ & $158(31)$ & \\
\hline \multicolumn{7}{|l|}{ HER2 } \\
\hline Amplification & & & 0.09 & & & 0.19 \\
\hline Negative & $217(53)$ & $852(58)$ & & $176(51)$ & $293(58)$ & \\
\hline Positive & $37(9)$ & $202(14)$ & & $32(9)$ & $72(14)$ & \\
\hline N.A. & $154(38)$ & $422(29)$ & & $139(40)$ & $137(27)$ & \\
\hline Expression & & & 0.25 & & & 0.33 \\
\hline Negative & $218(53)$ & $889(60)$ & & $179(52)$ & $299(60)$ & \\
\hline Positive & $39(10)$ & $198(13)$ & & $33(10)$ & $69(14)$ & \\
\hline N.A. & $151(37)$ & $389(26)$ & & 135 (39) & $134(27)$ & \\
\hline Ki-67 & & & 0.08 & & & 0.07 \\
\hline Negative & $155(38)$ & $615(42)$ & & $133(38)$ & $209(42)$ & \\
\hline Positive & $73(18)$ & $379(26)$ & & $54(16)$ & $121(24)$ & \\
\hline N.A. & $180(44)$ & $482(33)$ & & $160(46)$ & $172(34)$ & \\
\hline p53 & & & 0.63 & & & 0.21 \\
\hline Negative & $171(42)$ & $786(53)$ & & $145(42)$ & $254(51)$ & \\
\hline Positive & $38(9)$ & $192(13)$ & & $31(9)$ & $73(15)$ & \\
\hline N.A. & $199(49)$ & 498 (34) & & $171(49)$ & $175(35)$ & \\
\hline Adjuvant systemic therapy & & & $<0.001$ & & & $<0.001$ \\
\hline Not given & $314(77)$ & $827(56)$ & & $271(78)$ & $297(59)$ & \\
\hline Given & $89(22)$ & $609(41)$ & & $72(21)$ & $197(39)$ & \\
\hline N.A. & $5(1)$ & $40(3)$ & & $4(1)$ & $8(2)$ & \\
\hline
\end{tabular}


Method of detection and breast cancer survival

Women with screen-detected breast cancer had more favorable BCSS than patients with non-screen-detected cancer. The 15-year BCSS rate for patients with screendetected breast cancer was $86 \%$, and for patients with non-screen-detected breast cancer it was $66 \%(P<$
0.0001, $R R=2.91, R R=$ risk ratio). The survival advantage was seen in tumor size categories 1 to $10 \mathrm{~mm}, 11$ to $20 \mathrm{~mm}$ and 21 to $50 \mathrm{~mm}$ (Figure 1). Only two patients available for analysis in the screen-detected group had tumors larger than $50 \mathrm{~mm}$, which did not allow a statistical comparison. Women with screen-

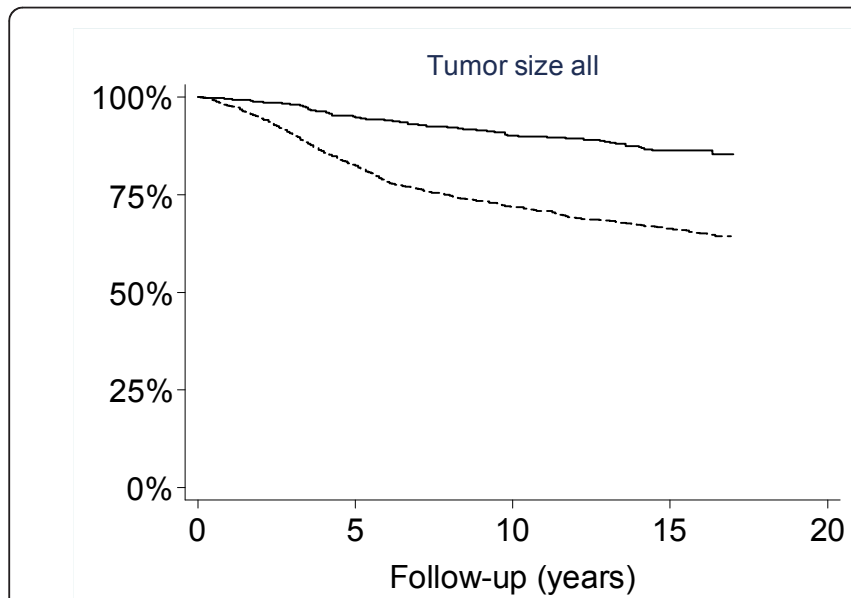

No. At risk

$\begin{array}{lllll}\text { screened } & 408 & 379 & 345 & 313\end{array}$

$\begin{array}{lllll}\text { non-scr } & 1476 & 1086 & 819 & 658\end{array}$

LogRank ChiSquared: 60,51 p<.0001 RR:2.91

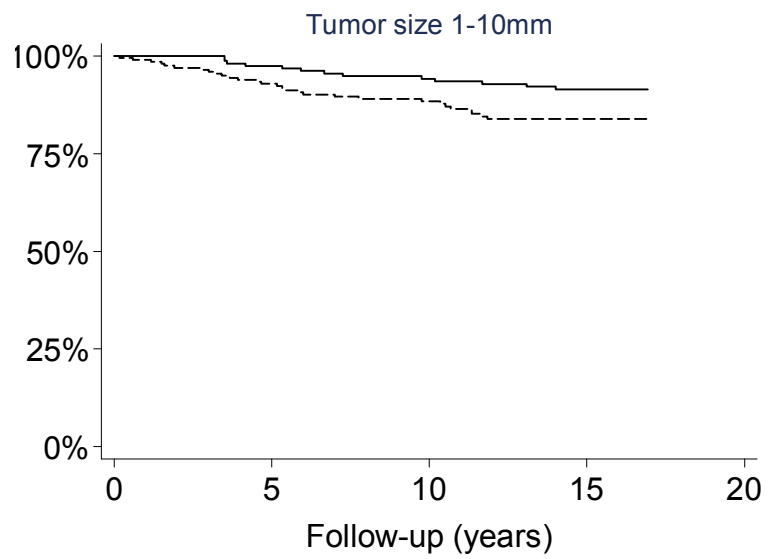

$\begin{array}{llll}158 & 153 & 142 & 132 \\ 207 & 175 & 143 & 116\end{array}$

LogRank ChiSquared: 4,73 p=.0296 RR:2.04
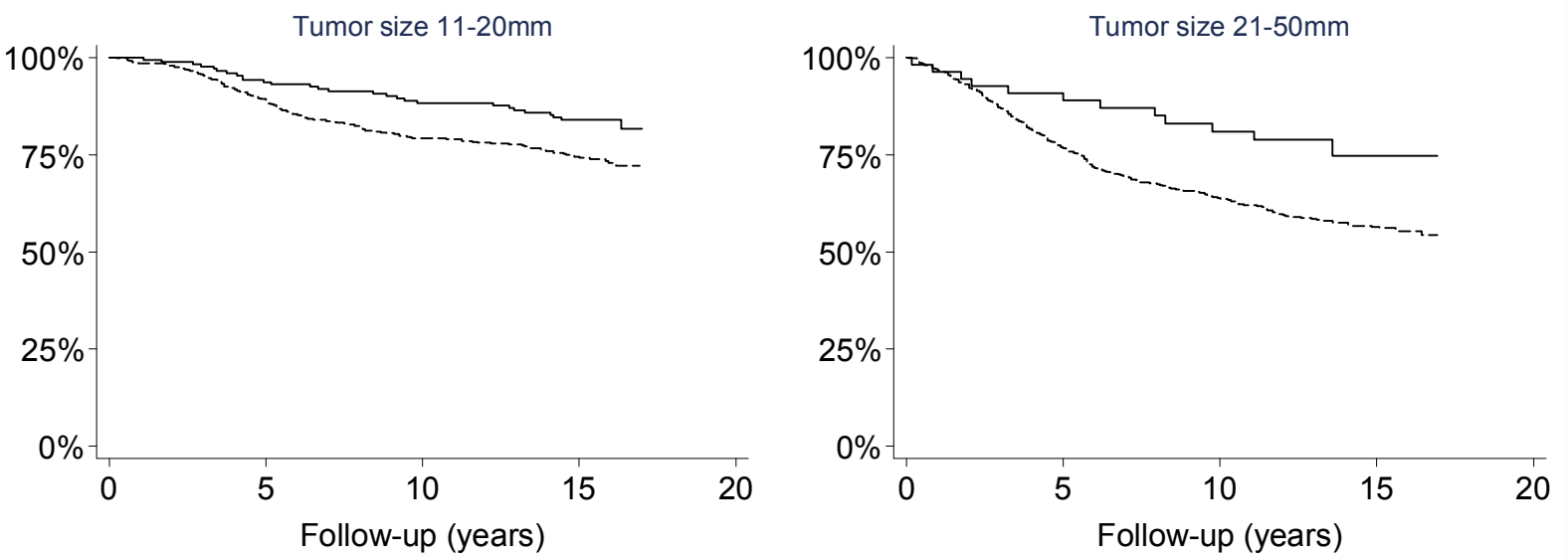

No. At risk

$\begin{array}{lllll}\text { screened } & 179 & 163 & 148 & 133\end{array}$

$\begin{array}{lllll}\text { non-scr } & 576 & 465 & 358 & 297\end{array}$

LogRank ChiSquared: 7,39 p=.0066 RR:1.75

$\begin{array}{llll}55 & 49 & 41 & 37 \\ 581 & 392 & 281 & 214\end{array}$

LogRank ChiSquared: 6,86 p<=.0088 RR:2.08

Figure 1 Breast cancer-specific survival by primary tumor size and mode of detection. Solid lines represent cancers detected by mammography screening, dashed lines represent cancers detected outside screening. 
detected T2 category tumors ( 21 to $50 \mathrm{~mm}$ ) had prognoses similar to those of patients with non-screendetected $\mathrm{T} 1$ category tumors (1 to $20 \mathrm{~mm})(15$-year BCSS 76.6\% vs 77\%; $P=0.863$ and $R R=0.95)($ Table 2$)$.

\section{Influence of screening on outcome according to nodal status}

This study included 1,203 (62\%) node-negative and 654 (34\%) node-positive breast cancer patients. Among the node-negative breast cancer patients, breast cancer was screen-detected in 317 patients $(78 \%)$ and non-screendetected in 862 patients $(58 \%)(P<0.001)$. In patients with screen-detected node-negative breast cancer, 15-year BCSS was $91 \%$ compared to $77 \%$ in the non-screendetected group $(P<0.0001$ and $R R=3)$. Patients with screen-detected, node-positive breast cancer had a survival advantage compared to patients diagnosed by other methods ( $71 \%$ vs $51 \%$, respectively; $P=0.0011$ and $R R=1.95)$.

\section{Influence of age at diagnosis on outcome}

In this study, there were 873 patients (45\%) ages 50 to 69 years, of whom 347 (40\%) were diagnosed by screening and $502(58 \%)$ were diagnosed on the basis of other methods. There was a statistically significant difference in 15-year BCSS between the two subgroups (15-year BCSS $86 \%$ for patients with screen-detected tumors and $68 \%$ for patients diagnosed by other methods; $P<$ 0.0001 and $R R=2.61$ ). Similar differences in survival were observed in all other age cohorts (Table 3 ).

\section{Multivariate survival analyses}

Screening mammography is commonly offered to women 50 to 69 years of age. Because the proportion of screen-detected cancers was different according to age groups, and since screen-detected tumors were smaller, less often node-positive, less often of the ductal type, more differentiated, and associated with a more favorable hormonal status, we performed a multivariate analysis to adjust for these factors. As a result, the method of tumor detection was an independent prognostic factor, with a hazard ratio (HR) of $1.69(95 \% \mathrm{CI}=1.06$ to 2.70) between patients whose tumors were detected outside screening and those whose tumors were screendetected. Tumor size, nodal status, tumor grade and HER2 amplification OK were also independent of other variables (Table 4). The HR for the method of detection was $1.48(95 \% \mathrm{CI}=0.97$ to 2.25$)$ in the first sensitivity analysis and 1.45 (95\% CI $=0.97$ to 2.17 ) in the second sensitivity analysis.

\section{Contralateral breast cancer}

Differences in the probability of having future contralateral breast cancer between screen-detected and nonscreen-detected breast cancer patients during the 15year follow-up time were assessed. For this analysis, we used the same exclusion criteria that we applied in the main analysis, with the exception of later contralateral breast cancers. Without any adjustments according to other variables, there were no significant differences if the primary breast cancer was diagnosed by screening mammography or by other methods $(7.3 \%$ vs $6.8 \%$, respectively; $P=0.74$ and $\mathrm{OR}=0.96)$. When patients 50 to 69 years of age were analyzed, the results were similar (7.0\% vs $7.9 \%$, respectively; $P=0.60$, respectively). After adjustments according to the same covariates as those used in the Cox multivariate survival analyses, the risk

Table 2 Breast cancer-specific survival according to primary tumor diameter

\begin{tabular}{|c|c|c|c|c|c|c|}
\hline \multirow[b]{2}{*}{ Primary tumor diameter $(\mathrm{mm})$} & \multicolumn{2}{|c|}{ Screening } & \multicolumn{2}{|c|}{ Outside screening } & \multirow[b]{2}{*}{$P$ value } & \multirow[b]{2}{*}{ RR } \\
\hline & At risk $(n)$ & 15-year survival (\%) & At risk $(n)$ & 15-year survival (\%) & & \\
\hline \multicolumn{7}{|l|}{ All age groups } \\
\hline$\leq 10$ & 132 & 92.1 & 116 & 83.9 & 0.0296 & 2.04 \\
\hline 11 to 20 & 133 & 84 & 297 & 74.5 & 0.0066 & 1.75 \\
\hline 21 to 50 & 37 & 76.6 & 214 & 56.5 & 0.0088 & 2.08 \\
\hline$>50$ & N.A. & N.A. & 19 & 34.1 & N.A. & N.A. \\
\hline \multicolumn{7}{|l|}{ Ages 50 to 69 years } \\
\hline$\leq 10$ & 122 & 92.1 & 54 & 83.1 & 0.0343 & 2.25 \\
\hline 11 to 20 & 110 & 81.5 & 123 & 74.6 & 0.0764 & 1.52 \\
\hline 21 to 50 & 30 & 77.7 & 89 & 59.4 & 0.0325 & 1.02 \\
\hline$>50$ & N.A. & N.A. & 5 & 35.7 & N.A. & N.A. \\
\hline \multicolumn{7}{|l|}{ Node-negative ages 50 to 69 years } \\
\hline$\leq 10$ & 114 & 93.7 & 48 & 84 & 0.021 & 2.66 \\
\hline 11 to 20 & 84 & 87 & 89 & 79.3 & 0.0534 & 1.85 \\
\hline 21 to 50 & 19 & 90.7 & 58 & 70.9 & 0.0769 & 2.79 \\
\hline$>50$ & N.A. & N.A. & 2 & 50 & N.A. & N.A. \\
\hline
\end{tabular}

N.A. $=$ data not available because screen-detected tumors were rarely $>50 \mathrm{~mm} ; \mathrm{RR}=$ risk ratio. 
Table 3 Breast cancer-specific survival by method of detection and age at diagnosis

\begin{tabular}{|c|c|c|c|c|c|c|c|c|}
\hline \multirow[b]{3}{*}{ Age at diagnosis (years) } & \multicolumn{4}{|c|}{ Screening } & \multicolumn{4}{|c|}{ Outside screening } \\
\hline & \multicolumn{4}{|c|}{ Survival (\%) } & \multirow[b]{2}{*}{ Patients $(n)$} & \multicolumn{3}{|c|}{ Survival (\%) } \\
\hline & Patients ( $n$ ) & 5 years & 10 years & 15 years & & 5 years & 10 years & 15 years \\
\hline \multicolumn{9}{|c|}{ Node-negative and node-positive } \\
\hline$\leq 39$ & 2 & N.A. & N.A. & N.A. & 118 & 81.4 & 63.5 & 57.3 \\
\hline 40 to 49 & 47 & 100 & 93.5 & 93.5 & 362 & 85.6 & 75.8 & 71.3 \\
\hline 50 to 59 & 254 & 94.1 & 89.6 & 86.3 & 230 & 84.2 & 77.1 & 71.5 \\
\hline 60 to 69 & 93 & 97.8 & 92.1 & 84.9 & 272 & 83.3 & 71.2 & 65.8 \\
\hline$\geq 70$ & 12 & N.A. & N.A. & N.A. & 494 & 80.4 & 69.1 & 60.8 \\
\hline \multicolumn{9}{|l|}{ Node-negative } \\
\hline$\leq 39$ & 1 & N.A. & N.A. & N.A. & 64 & 92.2 & 81.2 & 76.3 \\
\hline 40 to 49 & 34 & 100 & 97.1 & 97.1 & 195 & 92.8 & 85.6 & 82.5 \\
\hline 50 to 59 & 190 & 98.4 & 95.2 & 92.4 & 150 & 92 & 86.5 & 82.3 \\
\hline 60 to 69 & 83 & 98.9 & 92.5 & 87.2 & 171 & 86.1 & 79.1 & 72.1 \\
\hline$\geq 70$ & 9 & N.A. & N.A. & N.A. & 282 & 88.6 & 78 & 70.7 \\
\hline \multicolumn{9}{|l|}{ Node-positive } \\
\hline$\leq 39$ & 1 & N.A. & N.A. & N.A. & 54 & 72.2 & 46.3 & 38.6 \\
\hline 40 to 49 & 12 & 100 & 91.7 & 91.7 & 165 & 76.9 & 64 & 57.8 \\
\hline 50 to 59 & 61 & 83.4 & 75 & 69.9 & 79 & 69.5 & 59.2 & 50.9 \\
\hline 60 to 69 & 8 & 100 & 100 & 71.4 & 99 & 78.4 & 58.4 & 55.6 \\
\hline$\geq 70$ & 3 & N.A. & N.A. & N.A. & 155 & 66 & 55.5 & 45.4 \\
\hline
\end{tabular}

N.A. $=$ data not available because screening was rarely performed in women ages $\leq 39$ and $\geq 70$.

of having later contralateral breast cancer was slightly increased in patients with breast cancer detected outside screening compared to patients with screen-detected breast cancer $(95 \% \mathrm{CI}=0.55$ to 2.57 and $\mathrm{OR}=1.18$ ), but the difference was not statistically significant.

\section{Discussion}

In the current study, we have shown that the outcome of breast cancer is significantly better in patients with mammography screen-detected tumors than in patients with tumors detected by other methods, even beyond 15 years after diagnosis. After adjustment for a series of potential confounders, patients whose tumors were detected during screening mammography had an approximately $41 \%$ lower risk of dying as a result of breast cancer than did those whose tumors were detected outside screening. These results are in accord with those of our previous studies $[9,17]$ in which we found significant survival differences over postdiagnostic follow-up durations up to 10 years.

The survival difference could not be explained by lead time- and length bias-related variables, such as extent of disease, histopathological and molecular prognostic factors. Similar results have been reported by others $[3,18,19,29]$ who have shown the method of detection to be an independent prognostic factor. An adjusted risk

Table 4 Cox multivariable analysis

\begin{tabular}{|c|c|c|}
\hline Variable & HR $(95 \% \mathrm{Cl})$ & $P$ value \\
\hline Detection outside screening & $1.69(1.06$ to 2.70$)$ & 0.028 \\
\hline Tumor size (per cm) & $1.02(1.01$ to 1.03$)$ & $<0.001$ \\
\hline Positive lymph nodes ( $n /$ metastatic node) & $1.31(1.10$ to 1.17$)$ & $<0.001$ \\
\hline Histological grade (grade II vs grade III vs grade I) & $2.54(1.52$ to 4.25$)$ & $<0.001$ \\
\hline PR (negative vs positive) & 1.23 (0.92 to 1.64$)$ & 0.154 \\
\hline HER2 amplification (positive vs negative) & 1.45 (1.06 to 1.97$)$ & 0.019 \\
\hline \multicolumn{3}{|l|}{ Age at diagnosis (years) } \\
\hline$\leq 39^{\mathrm{a}}$ & 1.00 & \\
\hline 40 to 49 & $0.62(0.28$ to 1.00$)$ & 0.051 \\
\hline 50 to 59 & $0.82(0.50$ to 1.34$)$ & 0.437 \\
\hline 60 to 69 & $0.92(0.57$ to 1.49$)$ & 0.733 \\
\hline$\geq 70$ & 1.13 (0.70 to 1.83$)$ & 0.605 \\
\hline
\end{tabular}


decrease ranging from $21 \%$ to $48 \%$ for patients detected within screening has been reported, which is similar to the effect size found in the current study $[3,18,19]$.

In agreement with previous studies, we found that screen-detected tumors were smaller and were less frequently node-positive than tumors detected outside screening. Screen-detected tumors were more often well-differentiated, of special histological type, hormone receptor-positive and showed lower proliferation as measured by Ki-67 expression. The only examined biomarker that was not significantly associated with the method of detection was HER2 amplification. A similar finding has previously been reported for HER2 expression $[2,6]$.

The adjusted HR (1.69) between patients with screendetected and non-screen-detected cancers according to BCSS was somewhat lower, with a median follow-up of 15.4 years compared to the HR (2.1) after 9.5 years follow-up in our previous study [17]. This finding could potentially be explained by a large proportion of patients who were excluded (contralateral breast cancer or other cancer) during the extended follow-up in the main analyses. It is not supported by the sensitivity analyses, however, because the HR was lower (1.47) when patients with contralateral cancers were included.

The risk of contralateral breast cancer among breast cancer survivors is reportedly two- to sixfold the risk of breast cancer in the general population [43]. The risk of having contralateral breast cancer among breast cancer survivors is associated with lobular or inflammatory histology of the primary breast cancer, family history of breast cancer and young age at the time of primary diagnosis [44-47]. To the best of our knowledge, the association between the method of detection of primary cancer and the risk of contralateral breast cancer has not been investigated previously. In current study, we found that the risk for contralateral breast cancer was similar in patients with screen-detected and non-screendetected cancers. However, the risk of contralateral breast cancer is reported to be significantly higher among women with primary in situ cancer [48]. The proportion of in situ cancers is higher in screendetected than in non-screen-detected cancers. Only patients with invasive breast cancers were included in the current study. Whether the risk of contralateral breast cancer is altered according to the method of detection in women with primary in situ cancer remains to be investigated. According to this study, the followup for contralateral breast cancer should be similar in patients with screen-detected and non-screen-detected invasive breast cancers.

In the current study, screen-detected cancer was defined according to true attendance at mammography screening. All other breast cancers, including those of patients who did not undergo mammography, were considered non-screen-detected. If we had included nonattendees in the screen-detected group, the survival estimates could be distorted, thus underestimating the survival advantage of screening. In a previous study, breast cancer mortality among the women invited to have mammographies was reduced by $22 \%$, whereas the mortality reduction was $28 \%$ among true attendees [49].

The use of adjuvant therapies was rather homogeneous during 1991 and 1992 in Finland. In this cohort, adjuvant therapy was given less frequently to patients with screen-detected tumors than to patients with breast cancer diagnosed by other methods. Thus the use of adjuvant therapies does not explain the survival advantage associated with screening in this study.

Although there were significant differences in the proportion of many commonly used prognostic factors between screen-detected and non-screen-detected tumors, the frequency of lobular carcinoma was similar in both groups. Lobular carcinomas are often difficult to detect by mammography because they are radiologically elusive [50,51]. Lobular carcinomas may also be difficult to detect clinically because they less commonly form a palpable mass [52], which may in part explain the similar proportion of lobular carcinomas in both groups.

Although we were able to adjust the HRs for the method of detection for an extensive series of known prognostic factors, survival differences remain to be explained. More detailed tumor profiling might aid in characterizing tumors and should be studied in future projects. The value of some commonly used prognostic factors is observed to diminish over prolonged follow-up times. In the present study, the screening benefit remained after long-term follow-up. According to this study, patients with screen-detected breast cancer may be overtreated if screening as a method of detection is not taken into account in risk estimation and therapy decision-making.

\section{Conclusions}

The method of detection is an independent prognostic factor for long-term survival among breast cancer patients. According to this study, screening as a method of detection may be considered a favorable prognostic factor in risk estimation and therapy decision-making to avoid overtreatment of screen-detected breast cancers.

\section{Additional material}

Additional file 1: Consort diagrams for main analyses, the first sensitivity analyses and the second sensitivity analyses.

Additional file 2: Table S1 Distribution of breast cancers in the FinProg data according to the method of measurement and the method of detection (exclusions according to main analyses, $N=$ 
1,884). Table S2 Adjustment according to tumor size after analyzing proportion of different grades in screen-detected and non-screendetected patients (exclusions according to main analyses, $N=1,884$ ).

\section{Abbreviations}

CISH: chromogenic in situ hybridization; ER: estrogen receptor; HER2: human epidermal growth factor receptor 2; PR: progesterone receptor.

\section{Acknowledgements}

This work was supported by the Sigrid Jusèlius Foundation (to $\mathrm{J}$ and $\mathrm{HJ}$ ), the Cancer Society of Finland (to $\mathrm{J} L$ and $\mathrm{HJ}$ ), the Academy of Finland (to $\mathrm{HJ}$ ), Helsinki University Central Hospital Research Funds (to $\mathrm{JL}$ and $\mathrm{HJ}$ ), the Biomedicum Helsinki Foundation (to $\mathrm{TL}$ ) and Finska Läkaresällskapet (to $\mathrm{J}$, $\mathrm{ML}$ and $\mathrm{NL}$ ).

\section{Author details}

1 Institute for Molecular Medicine Finland (FIMM), University of Helsinki, Biomedicum Helsinki 2U, Tukholmankatu 8, PO Box 20, Fl-00014 Helsinki, Finland. ${ }^{2}$ Molecular Cancer Biology Program, Biomedicum Helsinki, University of Helsinki, Tukholmankatu 8, PO Box 20, Fl-00014, Helsinki, Finland. ${ }^{3}$ Departments of Palliative Medicine and Oncology, Tampere University Hospital and University of Tampere, Teiskontie 35, PO Box 2000, Fl-33521, Tampere, Finland. ${ }^{4}$ Department of Oncology and Hematology, Oulu University Central Hospital, Kajaanintie 50, PO Box 20, Fl-90029, Oulu, Finland. ${ }^{5}$ Cancer Center, Kuopio University Central Hospital, Puijonlaaksontie 2, PO Box 1777, FI-70211, Kuopio, Finland. ${ }^{6}$ Institute of Medical Technology, University of Tampere and Tampere University Hospital, Biokatu 8-12, PO Box 2000, FI-33520,Tampere, Finland. 'Department of Oncology, Helsinki University Central Hospital, Haartmaninkatu 4, PO Box 180, Fl-00029, Helsinki, Finland. ${ }^{8}$ Division of Global Health, Karolinska Institutet, SE-17177, Stockholm, Sweden.

\section{Authors' contributions}

$T L, H J$ and $J L$ designed the study and drafted the manuscript. $H J$ initiated the FinProg study and organized the collection of clinical data. JL, ML, TL, $\mathrm{KH}, \mathrm{LE}, \mathrm{VK}, \mathrm{TTH}$ and Jl collected the clinical data. Jl organized the collection of tumor samples. TL collected the tissue for tissue microarrays. Jl, HS and $\mathrm{NL}$ interpreted the results of the immunohistochemical and in situ hybridization analysis. TL and JL performed the statistical analyses. All authors critically revised the manuscript and approved its final form.

\section{Competing interests}

The authors declare that they have no competing interests.

Received: 1 July 2011 Revised: 22 December 2011

Accepted: 28 December 2011 Published: 28 December 2011

\section{References}

1. Porter PL, El-Bastawissi AY, Mandelson MT, Lin MG, Khalid N, Watney EA, Cousens L, White D, Taplin S, White E: Breast tumor characteristics as predictors of mammographic detection: comparison of interval- and screen-detected cancers. J Natl Cancer Inst 1999, 91:2020-2028.

2. Dawson SJ, Duffy SW, Blows FM, Driver KE, Provenzano E, LeQuesne J, Greenberg DC, Pharoah P, Caldas C, Wishart GC: Molecular characteristics of screen-detected vs symptomatic breast cancers and their impact on survival. Br J Cancer 2009, 101:1338-1344.

3. Shen Y, Yang Y, Inoue LY, Munsell MF, Miller AB, Berry DA: Role of detection method in predicting breast cancer survival: analysis of randomized screening trials. J Natl Cancer Inst 2005, 97:1195-1203.

4. Burrell HC, Sibbering DM, Wilson AR, Pinder SE, Evans AJ, Yeoman L, Elston CW, Ellis IO, Blamey RW, Robertson JF: Screening interval breast cancers: mammographic features and prognosis factors. Radiology 1996, 199:811-817.

5. Cady B, Stone MD, Schuler JG, Thakur R, Wanner MA, Lavin PT: The new era in breast cancer: invasion, size, and nodal involvement dramatically decreasing as a result of mammographic screening. Arch Surg 1996, 131:301-308.
6. Pálka I, Kelemen G, Ormándi K, Lázár G, Nyári T, Thurzó L, Kahán Z: Tumor characteristics in screen-detected and symptomatic breast cancers. Pathol Oncol Res 2008, 14:161-167.

7. Cady B: New era in breast cancer: impact of screening on disease presentation. Surg Oncol Clin N Am 1997, 6:195-202.

8. Paci E, Duffy SW, Giorgi D, Zappa M, Crocetti E, Vezzosi V, Bianchi S, Cataliotti L, del Turco MR: Are breast cancer screening programmes increasing rates of mastectomy? Observational study. BMJ 2002, 325:418.

9. Sihto H, Lundin J, Lehtimäki T, Sarlomo-Rikala M, Bützow R, Holli K, Sailas L, Kataja V, Lundin M, Turpeenniemi-Hujanen T, Isola J, Heikkilä P, Joensuu H: Molecular subtypes of breast cancers detected in mammography screening and outside of screening. Clin Cancer Res 2008, 14:4103-4110.

10. Crosier M, Scott D, Wilson RG, Griffiths CDM, May FEB, Westley BR: Differences in Ki67 and c-erbB2 expression between screen-detected and true interval breast cancers. Clin Cancer Res 1999, 5:2682-2688.

11. Groenendijk RP, Bult P, Tewarie L, Peer PG, van der Sluis RF, Ruers TJ, Wobbes T: Screen-detected breast cancers have a lower mitotic activity index. Br J Cancer 2000, 82:381-384.

12. Dong W, Berry DA, Bevers TB, Kau SW, Hsu L, Theriault RL, Shen Y: Prognostic role of detection method and its relationship with tumor biomarkers in breast cancer: the University of Texas M.D. Anderson Cancer Center experience. Cancer Epidemiol Biomarkers Prev 2008, 17:1096-1103.

13. Ernst MF, Roukema JA, Coebergh JW, Repelaer van Driel OJ, van Beek MW, van der Sangen MJ, Voogd AC: Breast cancers found by screening: earlier detection, lower malignant potential or both? Breast Cancer Res Treat 2002, 76:19-25.

14. Gabriel H, Wilson TE, Helvie MA: Breast cancer in women 65-74 years old: earlier detection by mammographic screening. AJR Am J Roentgenol 1997, 168:23-27.

15. Anttinen J, Kuopio T, Nykanen M, Torkkeli H, Saari U, Juhola M: Her-2/neu oncogene amplification and protein over-expression in interval and screen-detected breast cancers. Anticancer Res 2003, 23:4213-4218.

16. Klemi PJ, Toikkanen S, Räsänen O, Parvinen I, Joensuu H: Mammography screening interval and the frequency of interval cancers in a populationbased screening. Br J Cancer 1997, 75:762-766.

17. Joensuu H, Lehtimäki T, Holli K, Elomaa L, Turpeenniemi-Hujanen T, Kataja V, Anttila A, Lundin M, Isola J, Lundin J: Risk for distant recurrence of breast cancer detected by mammography screening or other methods. JAMA 2004, 292:1064-1073.

18. Mook S, Van 't Veer LJ, Rutgers EJ, Ravdin PM, van de Velde AO, van Leeuwen FE, Visser O, Schmidt MK: Independent prognostic value of screen detection in invasive breast cancer. J Natl Cancer Inst 2011, 103:585-597.

19. Wishart GC, Greenberg DC, Britton PD, Chou P, Brown CH, Purushotham AD, Duffy SW: Screen-detected vs symptomatic breast cancer: is improved survival due to stage migration alone? $\mathrm{Br} /$ Cancer 2008, 98:1741-1744.

20. Immonen-Räihä P, Kauhava L, Parvinen I, Holli K, Kronqvist P, Pylkkänen L, Helenius $\mathrm{H}$, Kaljonen A, Räsänen O, Klemi PJ: Mammographic screening reduces risk of breast carcinoma recurrence. Cancer 2005, 103:474-482

21. Nagtegaal ID, Allgood PC, Duffy SW, Kearins O, Sullivan EO, Tappenden N, Wallis M, Lawrence G: Prognosis and pathology of screen-detected carcinomas: how different are they? Cancer 2011, 117:1360-1368

22. Jatoi I, Anderson WF, Jeong JH, Redmond CK: Breast cancer adjuvant therapy: time to consider its time-dependent effects. J Clin Oncol 2011, 29:2301-2304, A published erratum appears in J Clin Oncol 2011, 29:3948.

23. Brenner $\mathrm{H}$, Hakulinen $\mathrm{T}$ : Are patients diagnosed with breast cancer before age 50 years ever cured? J Clin Oncol 2004, 22:432-438.

24. Joensuu H, Pylkkänen L, Toikkanen S: Late mortality from pT1NOMO breast carcinoma. Cancer 1999, 85:2183-2189.

25. Joensuu H, Toikkanen S: Cured of breast cancer? J Clin Oncol 1995, 13:62-69.

26. Warwick J, Tabár L, Vitak B, Duffy SW: Time-dependent effects on survival in breast carcinoma: results of 20 years of follow-up from the Swedish Two-County Study. Cancer 2004, 100:1331-1336.

27. Anderson WF, Chen BE, Jatoi I, Rosenberg PS: Effects of estrogen receptor expression and histopathology on annual hazard rates of death from breast cancer. Breast Cancer Res Treat 2006, 100:121-126.

28. Tabár L, Vitak B, Chen TH, Yen AM, Cohen A, Tot T, Chiu SY, Chen SL, Fann JC, Rosell J, Fohlin H, Smith RA, Duffy SW: Swedish Two-County Trial: 
impact of mammographic screening on breast cancer mortality during 3 decades. Radiology 2011, 260:658-663.

29. Tabár L, Duffy SW, Vitak B, Chen HH, Prevost TC: The natural history of breast carcinoma: what have we learned from screening? Cancer 1999, 86:449-462.

30. Woloshin S, Schwartz LM: The benefits and harms of mammography screening: understanding the trade-offs. JAMA 2010, 303:164-165.

31. Murphy AM: Mammography screening for breast cancer: a view from 2 worlds. JAMA 2010, 303:166-167.

32. Kopans DB, Monsees B, Feig SA: Screening for cancer: when is it valid? Lessons from the mammography experience. Radiology 2003, 229:319-327.

33. Zahl PH, Strand BH, Maehlen J: Incidence of breast cancer in Norway and Sweden during introduction of nationwide screening: prospective cohort study. BMJ 2004, 328:921-924.

34. de Koning $\mathrm{HJ}$ : Why improvement in survival of screen-detected cases is not necessarily equivalent to benefit? Breast 2003, 12:299-301.

35. Duffy SW, Nagtegaal ID, Wallis M, Cafferty FH, Houssami N, Warwick J, Allgood PC, Kearins O, Tappenden N, O'Sullivan E, Lawrence G: Correcting for lead time and length bias in estimating the effect of screen detection on cancer survival. Am J Epidemiol 2008, 168:98-104.

36. Berg WA: Benefits of screening mammography. JAMA 2010, 303:168-169.

37. Olivotto IA, Mates D, Kan L, Fung J, Samant R, Burhenne LJ: Prognosis, treatment, and recurrence of breast cancer for women attending or not attending the Screening Mammography Program of British Columbia. Breast Cancer Res Treat 1999, 54:73-81.

38. Kononen J, Bubendorf $L$, Kallioniemi A, Bärlund M, Schraml P, Leighton $S$, Torhorst J, Mihatsch MJ, Sauter G, Kallioniemi OP: Tissue microarrays for high-throughput molecular profiling of tumor specimens. Nat Med 1998, 4:844-847.

39. World Health Organization: The World Health Organization Histological Typing of Breast Tumors-Second Edition. Am J Clin Pathol 1982, 78:806-816.

40. Joensuu H, Isola J, Lundin M, Salminen T, Holli K, Kataja V, Pylkkänen L, Turpeenniemi-Hujanen T, von Smitten K, Lundin J: Amplification of erbB2 and erbB2 expression are superior to estrogen receptor status as risk factors for distant recurrence in PT1NOMO breast cancer: a nationwide population-based study. Clin Cancer Res 2003, 9:923-930.

41. Tanner M, Gancberg D, Di Leo A, Larsimont D, Rouas G, Piccart MJ, Isola J: Chromogenic in situ hybridization: a practical alternative for fluorescence in situ hybridization to detect HER-2/neu oncogene amplification in archival breast cancer samples. Am J Pathol 2000, 157:1467-1472

42. Hammond ME, Hayes DF, Dowsett M, Allred DC, Hagerty KL, Badve S, Fitzgibbons PL, Francis G, Goldstein NS, Hayes M, Hicks DG, Lester S, Love R, Mangu PB, MCShane L, Miller K, Osborne CK, Paik S, Perlmutter J, Rhodes A, Sasano H, Schwartz JN, Sweep FC, Taube S, Torlakovic EE, Valenstein P, Viale G, Visscher D, Wheeler T, Williams RB, Wittliff JL, Wolff AC: American Society of Clinical Oncology/College Of American Pathologists guideline recommendations for immunohistochemical testing of estrogen and progesterone receptors in breast cancer. J Clin Oncol 2010, 28:2784-2795, A published erratum appears in J Clin Oncol 2010, 28:3543.

43. Rubino C, Arriagada R, Delaloge S, Lê MG: Relation of risk of contralateral breast cancer to the interval since the first primary tumour. $\mathrm{Br} J$ Cancer 2010, 102:213-219.

44. Chen Y, Thompson W, Semenciw R, Mao Y: Epidemiology of contralateral breast cancer. Cancer Epidemiol Biomarkers Prev 1999, 8:855-861.

45. Horn PL, Thompson WD: Risk of contralateral breast cancer: associations with histologic, clinical, and therapeutic factors. Cancer 1988, 62:412-424.

46. Schairer C, Brown LM, Mai PL: Inflammatory breast cancer: high risk of contralateral breast cancer compared to comparably staged noninflammatory breast cancer. Breast Cancer Res Treat 2011, 129:117-124.

47. Yi M, Meric-Bernstam F, Middleton LP, Arun BK, Bedrosian I, Babiera GV, Hwang RF, Kuerer HM, Yang W, Hunt KK: Predictors of contralateral breast cancer in patients with unilateral breast cancer undergoing contralateral prophylactic mastectomy. Cancer 2009, 115:962-971.

48. Habel LA, Moe RE, Daling JR, Holte S, Rossing MA, Weiss NS: Risk of contralateral breast cancer among women with carcinoma in situ of the breast. Ann Surg 1997, 225:69-75.
49. Sarkeala $T$, Heinävaara $S$, Anttila A: Organised mammography screening reduces breast cancer mortality: a cohort study from Finland. Int J Cancer 2008, 122:614-619.

50. $\mathrm{Li} \mathrm{Cl}$, Anderson BO, Daling JR, Moe RE: Trends in incidence rates of invasive lobular and ductal breast carcinoma. JAMA 2003, 289:1421-1424.

51. Ma L, Fishell E, Wright B, Hanna W, Allan S, Boyd NF: Case-control study of factors associated with failure to detect breast cancer by mammography. J Natl Cancer Inst 1992, 84:781-785.

52. Lopez JK, Bassett LW: Invasive lobular carcinoma of the breast: spectrum of mammographic, US, and MR imaging findings. Radiographics 2009, 29:165-176.

doi: $10.1186 / \mathrm{bcr} 3080$

Cite this article as: Lehtimäki et al.: Long-term prognosis of breast

cancer detected by mammography screening or other methods. Breast

Cancer Research 2011 13:R134.

\section{Submit your next manuscript to BioMed Central and take full advantage of:}

- Convenient online submission

- Thorough peer review

- No space constraints or color figure charges

- Immediate publication on acceptance

- Inclusion in PubMed, CAS, Scopus and Google Scholar

- Research which is freely available for redistribution

Submit your manuscript at www.biomedcentral.com/submit
Ciomed Central 